\title{
Acute postprandial effect of hydrogenated fish oil, palm oil and lard on plasma cholesterol, triacylglycerol and non-esterified fatty acid metabolism in normocholesterolaemic males
}

\author{
Marie M. Cantwell ${ }^{1,2,3}$, Mary A.T. Flynn ${ }^{1,2,4}$ and Michael J. Gibney ${ }^{2 *}$ \\ ${ }^{1}$ Department of Biological Sciences, Dublin Institute of Technology, Kevin Street, Dublin 8, Republic of Ireland \\ ${ }^{2}$ Department of Clinical Medicine, Trinity Centre for Health Sciences, University of Dublin, Trinity College, Dublin 8 , \\ Republic of Ireland \\ ${ }^{3}$ Cancer Prevention Fellowship Program, Division of Cancer Prevention, National Cancer Institute, National Institutes of Health, \\ Bethesda, MD, USA \\ ${ }^{4}$ Department of Community Health Sciences, University of Calgary, Alberta, Canada
}

(Received 31 May 2005 - Revised 8 December 2005 - Accepted 9 December 2005)

\begin{abstract}
The majority of research has focused on the association between trans unsaturated fatty acids (TUFA) from hydrogenated vegetable oils and heart disease even though TUFA are also produced from hydrogenated fish oil. We compared the acute effect of three solid fats on postprandial cholesterol, triacylglycerol (TAG) and NEFA concentrations in normocholesterolaemic males. Eight healthy male volunteers consumed each of the three $40 \mathrm{~g}$ fat meals (partially hydrogenated fish oil (PHFO), palm oil and lard) in random order and blood samples were drawn at 2, 4, 6 and $8 \mathrm{~h}$ thereafter for lipid analysis. The postprandial response in plasma TAG, TAG-rich lipoprotein-TAG (TRL-TAG), total cholesterol and plasma NEFA, measured as the area under the postprandial curve, was not significantly different between the three meals $(P>0.05)$, which varied in MUFA, PUFA and TUFA content. There was no marked elevation of longer-chain fatty acids (C20-22, cis or trans isomers) into the TRL-TAG fraction following the PHFO meal even though they provided $40 \%$ of the total fatty acids in the PHFO meal. The postprandial TRL-TAG response to PHFO was expected to be higher, as it is higher in TUFA, lower in PUFA and similar in saturated fatty acid composition compared with the lard and palm oil test meals. The absence of a higher postprandial response following ingestion of PHFO could be as a result of reduced absorption and increased oxidation of long-chain fatty acids (both cis and trans isomers).
\end{abstract}

Hydrogenated fish oil: Trans unsaturated fatty acids: Palm oil: Lard: Postprandial response

Postprandial lipaemia refers to the series of events which occurs following ingestion, absorption and metabolism of a fat-rich meal and it is well understood that a prolonged and elevated response precipitates a number of adverse metabolic events. These include the production of atherogenic chylomicron remnants, small dense LDL particles, a reduction in beneficial HDL-cholesterol, and an adverse effect on the process of thrombosis. It is therefore of benefit to identify fats which produce a lower postprandial response and therefore a lower risk of developing CHD (Zilversmit, 1979; Patsch et al. 1992; Karpe et al. 1993). The acute postprandial response to varying amounts and types of fat has been studied extensively with the exception of fats high in trans unsaturated fatty acids (TUFA).

Animal fats such as lard, and partially hydrogenated oils, are commonly used in the food industry as components of margarine and processed foods because of their solidity and higher melting points. There is a consensus, however, that saturated fatty acids (SFA), from animal fats, and TUFA, from partially hydrogenated oils, should be reduced in the diet of the general population (Expert Panel on Detection, Evaluation and Treatment of High Blood Cholesterol in Adults, 2001). It is recommended that SFA and TUFA should provide no more than $7 \%$ (Expert Panel on Detection, Evaluation and Treatment of High Blood Cholesterol in Adults, 2001 ) and $2 \%$ of energy intake respectively (Department of Health, 1991). Dietary reference intakes are not available for SFA or TUFA intake, as increased risk exists at levels above zero. The Institute of Medicine therefore does not provide an upper limit of intake and recommends eating as little as possible of these fats (National Academy of Sciences, 2002).

Habitual intake of TUFA from partially hydrogenated vegetable oils has been shown to increase levels of plasma total and LDL-cholesterol levels (Mensink \& Katan, 1990; Nestel et al. 1992), lower plasma HDL-cholesterol (Zock \& Katan, 1992) and increase lipoprotein(a) (Mensink et al. 1992;

Abbreviations: AUC, area under the postprandial curve; $\mathrm{C}_{\max }$, maximum postprandial concentration; $\mathrm{C}_{\min }$, minimum postprandial concentration; PHFO, partially hydrogenated fish oil; PHSO, partially hydrogenated soyabean oil; SFA, saturated fatty acid; TAG, triacylglycerol; $\mathrm{T}_{\max }$, time to maximum postprandial concentration; TRL, triacylglycerol-rich lipoprotein; TUFA, trans unsaturated fatty acid.

* Corresponding author: Professor Michael J. Gibney, fax +3531454 2043, email mgibney@tcd.ie 
Almendingen et al. 1995). Recommendations to reduce dietary TUFA intake have been made based on these lipid studies along with evidence from epidemiological studies that have shown an increased risk of CVD (Ascherio et al. 1994) and acute myocardial infarction (Willett et al. 1993) with an increased TUFA intake. Studies which have examined the effects of TUFA on plasma lipids and lipoproteins have used hydrogenated vegetable oils, and there is currently very little information regarding TUFA from hydrogenated fish oil, fats which are also used by the food industry. Of the few studies which have examined the effect of TUFA from partially hydrogenated fish oils (PHFO), results indicate that PHFO is at least as potent as butterfat, and significantly more potent than partially hydrogenated soyabean oil (PHSO) in raising both plasma total and LDL-cholesterol levels (Almendingen et al. 1995). In addition, Muller et al. (1998) reported LDL-cholesterol concentrations which were $19 \%$ higher in participants after 2 weeks of consuming a margarine based on PHFO compared with a margarine based on vegetable oils. The LDL:HDL ratio was $12.6 \%$ higher in participants on the PHFO margarine compared with those on the vegetable oil margarine.

The issue arises as to whether there are benefits to replacing a product which is rich in SFA, such as lard, with a product which is not only rich in SFA, but which is also rich in TUFA, such as PHFO. The effect of TUFA on blood lipids and lipoprotein concentrations has been studied following long-term (21 d) ingestion of TUFA compared with oleic acid (18:1; Judd et al. 1994), linoleic acid (18:2n-6; Lichtenstein et al. 1993), or PHSO and butter (Almendingen et al. 1995). The reported effects of TUFA, in these long-term experiments, represent a steady state of production and catabolism. They do not provide insight into the mechanism by which TUFA may interfere with the complex process of assembly, secretion and metabolism of lipoproteins. The acute postprandial lipaemic effects of TUFA on lipid and lipoprotein levels is therefore of interest but has not been studied extensively.

The aim of the present study was two-fold. Since it is known that a prolonged and elevated acute postprandial response is associated with adverse metabolic events, we wanted to compare the lipaemic response to PHFO, lard and palm oil, three textured fats commonly used by the food industry. This may help to assess whether there are benefits to replacing a product which is rich in SFA, such as lard, with a product which is not only rich in SFA, but which is also rich in TUFA, such as PHFO. In addition we were interested in knowing how long-chain TUFA from PHFO are absorbed and cleared from plasma.

\section{Methods}

\section{Study design}

The participants were eight healthy men with a mean age of 26.1 (SD 3.1) years, mean weight of 84.6 (SD 9.6) $\mathrm{kg}$ and a mean BMI of 25.7 (SD 2.2) $\mathrm{kg} / \mathrm{m}^{2}$ and were recruited from the personnel of St James's Hospital, Dublin, Republic of Ireland. The study was approved by the Ethics Committee of the Federated Dublin Voluntary Hospital and all participants gave informed consent. The following inclusion criteria were used: BMI $20-30 \mathrm{~kg} / \mathrm{m}^{2}$, fasting plasma cholesterol $<6.5 \mathrm{mmol} / \mathrm{l}$, fasting plasma triacylglycerol (TAG) $<2.0 \mathrm{mmol} / \mathrm{l}, \mathrm{Hb}>13.0 \mathrm{~g} / \mathrm{dl}$ and $\gamma$-glutamyl transferase $<50$ units, $<90 \mathrm{~min}$ strenuous exercise per week and participants could not be habitual consumers of any fatty acid supplement or medication known to affect lipid metabolism.

Participants were asked to refrain from eating oily fish or from doing strenuous exercise for $24 \mathrm{~h}$ and to fast for $12 \mathrm{~h}$ before the test day. A 21 gauge, $32 \mathrm{~mm}$ venous catheter (Abbott Ireland Ltd, Dublin, Republic of Ireland) was inserted into the antecubital vein of the forearm and a fasting sample was collected. One of the three test meals was then taken by each volunteer and blood samples were drawn at 2, 4, 6 and $8 \mathrm{~h}$ for lipid analysis. Each volunteer ingested each of three test meals using a Latin square design and a 2-week wash-out period between test meals.

\section{Test meal composition}

The test meals were liquid blends of $40 \mathrm{~g}$ of one of the test fats (lard, PHFO (Trilby Trading Ltd, Republic of Ireland) or palm oil) gently melted and whisked with $150 \mathrm{ml}$ skimmed milk, $15 \mathrm{~g}$ skimmed milk powder (Tesco) and $15 \mathrm{~g}$ chocolate flavouring (Nestlé, Vevey, Switzerland) to form a homogeneous drink. Pasteurised egg-yolk powder (Lactosan UK Ltd, Braintree, Essex, UK) was added to the lard (2.83 g) and palm oil $(4 \cdot 2 \mathrm{~g})$ test meals to equalise the cholesterol composition of the test meals (Tables 1 and 2).

\section{Biochemical analysis}

Following collection, blood samples were immediately centrifuged at $2500 \mathrm{rpm}$ for $15 \mathrm{~min}$, then the plasma was harvested, sampled and stored at $-20^{\circ} \mathrm{C}$. Enzymic colourimetric assays were used to determine plasma TAG, TAG-rich lipoprotein (TRL)-TAG (TAG PAP; Biomerieux, Lyon, France), plasma cholesterol (Chol PAP; Biomerieux) and plasma NEFA concentrations (acyl Co A synthase-acyl Co A oxidase; Wako Chemicals, GmbH, Neuss, Germany) on a RA-XT clinical chemistry analyser (Technicon Inc., Tarrytown, NY, USA). The NEFA enzymic colourimetric assay may underestimate the concentration of longer-chain fatty acids as the enzyme acyl-CoA synthetase does not measure $\mathrm{C} 20$ and $\mathrm{C} 22$ fatty acid composition accurately (Shimizu et al. 1980). The inter-assay CV were $2.5 \%$ for plasma TAG, $2.4 \%$ for TRL-TAG, $1.48 \%$ for cholesterol and $3.84 \%$ for NEFA.

Plasma for TRL separation was stored overnight $\left(2-5^{\circ} \mathrm{C}\right)$. The plasma TRL fraction (chylomicrons) was prepared using a modified version of Grundy \& Mok (1976), as follows. Two $4.7 \mathrm{ml}$ Optiseal polyallomer centrifugation tubes (Beckman Instruments Inc., Palo Alto, CA, USA) were required for each sample's TRL separation. Plasma $(1.6 \mathrm{ml})$ was placed into each tube and overlaid with $1.6 \mathrm{ml}$ saline (density $1.006 \mathrm{~g} / \mathrm{ml}$ ). The TRL fraction was isolated by ultracentrifugation $\left(100000 \mathrm{rpm}\right.$ for $24 \mathrm{~min}\left(2.2 \times 10^{6} \mathrm{~g} / \mathrm{min}\right)$, at $\left.4^{\circ} \mathrm{C}\right)($ Beckman Optima TLX ultracentrifuge, Beckman Instruments Inc.), harvested and stored $\left(-20^{\circ} \mathrm{C}\right)$ for subsequent analysis.

The procedure of Folch et al. (1957) was used to extract TRLTAG and the lipid component of plasma was extracted using the procedure of Dole (1956), for NEFA analysis. The TAG fraction of TRL samples and the NEFA fraction of plasma samples were 
Table 1. Test meal composition (g)

\begin{tabular}{|c|c|c|c|c|c|c|}
\hline \multirow[b]{2}{*}{ Meal } & \multicolumn{2}{|c|}{ PHFO } & \multicolumn{2}{|c|}{ Lard $^{*}$} & \multicolumn{2}{|c|}{ Palm oil† } \\
\hline & g & Energy \% & g & Energy \% & g & Energy \% \\
\hline Energy (kJ) & \multicolumn{2}{|c|}{$2596 \cdot 4$} & \multicolumn{2}{|c|}{2675.8} & \multicolumn{2}{|c|}{2714.04} \\
\hline Protein & $17 \cdot 5$ & $11 \cdot 3$ & $18 \cdot 4$ & 11.5 & $18 \cdot 79$ & $11 \cdot 6$ \\
\hline Carbohydrate & $38 \cdot 1$ & $24 \cdot 6$ & $38 \cdot 1$ & $23 \cdot 9$ & $38 \cdot 1$ & $23 \cdot 6$ \\
\hline Fat & $45 \cdot 0$ & $65 \cdot 5$ & $45 \cdot 7$ & $64 \cdot 5$ & $46 \cdot 5$ & 64.9 \\
\hline SFA & $18 \cdot 9$ & $27 \cdot 5$ & $19 \cdot 2$ & $27 \cdot 1$ & $21 \cdot 2$ & $29 \cdot 6$ \\
\hline MUFA & $6 \cdot 2$ & $9 \cdot 1$ & $18 \cdot 3$ & $25 \cdot 9$ & $17 \cdot 8$ & 24.9 \\
\hline PUFA & $2 \cdot 0$ & $2 \cdot 9$ & $3 \cdot 8$ & $5 \cdot 4$ & $3 \cdot 3$ & $4 \cdot 6$ \\
\hline Trans unsaturated fatty acids & $15 \cdot 8$ & $23 \cdot 0$ & 0.56 & 0.79 & 0.0 & 0.0 \\
\hline Cholesterol (mg) & \multicolumn{2}{|c|}{$106 \cdot 8$} & \multicolumn{2}{|c|}{$110 \cdot 8$} & \multicolumn{2}{|c|}{$110 \cdot 8$} \\
\hline
\end{tabular}

PHFO, partially hydrogenated fish oil; SFA, saturated fatty acids.

* Pasteurised egg-yolk powder added $(2.83 \mathrm{~g})$

† Pasteurised egg-yolk powder added $(4 \cdot 2 \mathrm{~g})$.

isolated using TLC on silica 60LKD 19-lane TLC plates (Whatman, Clifton, NJ, USA) using a solvent system of light petroleum $\left(40-60^{\circ} \mathrm{C}\right)$, diethyl ether and formic acid $(80: 20: 2$, by vol.) (Gibney \& Bolton-Smith, 1988).

Component fatty acids were methylated using $\mathrm{BF}_{3}$ in methanol. GLC was used to identify fatty acid methyl esters of TRL-TAG and plasma NEFA fractions taken at 0,4 and $8 \mathrm{~h}$ postprandially, using a $100 \mathrm{~m}$ capillary column (SP 2560, $0.25 \mathrm{~mm}, 0.2 \mu \mathrm{m}$ ) and the following temperature program; starting temperature $175^{\circ} \mathrm{C}$, held for $35 \mathrm{~min}$, increased by $2.5^{\circ} \mathrm{C} / \mathrm{min}$ to $220^{\circ} \mathrm{C}$, held for $15 \mathrm{~min}$, increased by $2.5^{\circ} \mathrm{C} / \mathrm{min}$ to $240^{\circ} \mathrm{C}$, and held for $14 \mathrm{~min}$ (Hodgson et al. 1996). A split ratio of $1: 50$, and a flow rate of $0.7 \mathrm{ml} / \mathrm{min}$ and an injection volume of $1 \mu \mathrm{l}$ were used.

The molar \% of fatty acids was calculated in both the PHFO test meal and in the $4 \mathrm{~h}$ TRL-TAG samples following consumption of the PHFO meal as follows. The number of moles of each individual fatty acid in the PHFO test meal or

Table 2. Fatty acid composition of the three test fats used ( $\mathrm{g} / 100 \mathrm{~g}$ fatty acids)*

\begin{tabular}{|c|c|c|c|}
\hline Meal & PHFO & Lard & Palm oi \\
\hline $12: 0$ & 0.1 & 0.0 & 0.2 \\
\hline $14: 0$ & $7 \cdot 7$ & $2 \cdot 8$ & 1.1 \\
\hline $16: 0$ & $19 \cdot 1$ & $26 \cdot 2$ & 41.6 \\
\hline $16: 1 \mathrm{cis}$ & $1 \cdot 8$ & $4 \cdot 0$ & 0.3 \\
\hline $16: 1$ trans & 4.6 & 0.9 & 0.0 \\
\hline $18: 0$ & $6 \cdot 6$ & $17 \cdot 0$ & $4 \cdot 3$ \\
\hline $18: 1 \mathrm{cis}$ & $5 \cdot 1$ & $37 \cdot 2$ & 43.4 \\
\hline 18: 1 trans & 9.9 & $2 \cdot 1$ & 0.0 \\
\hline $18: 2$ cis & 0.7 & $1 \cdot 1$ & 8.4 \\
\hline $18: 2$ trans & $2 \cdot 3$ & 0.2 & 0.0 \\
\hline $18: 3$ & 0.0 & 0.3 & 0.3 \\
\hline $20: 0$ & 2.9 & 0.2 & 0.0 \\
\hline $20: 1$ cis & 3.7 & 0.0 & 0.0 \\
\hline $20: 1$ trans & 5.7 & 0.0 & 0.0 \\
\hline $20: 2$ cis & 1.9 & 0.0 & 0.0 \\
\hline $20: 2$ trans & $3 \cdot 1$ & 0.0 & 0.0 \\
\hline $22: 0$ & $3 \cdot 6$ & 0.0 & 0.0 \\
\hline $22: 1 \mathrm{cis}$ & $4 \cdot 8$ & 0.0 & 0.0 \\
\hline $22: 1$ trans & $7 \cdot 8$ & 0.0 & 0.0 \\
\hline 20 and C22trans PUFA† & 7.5 & 0.0 & 0.0 \\
\hline $15: 0+C 17: 0$ & $1 \cdot 2$ & 0.0 & 0.0 \\
\hline
\end{tabular}

PHFO, partially hydrogenated fish oil.

${ }^{*}$ Analysed in the study laboratory using GLC.

† Trans fatty acid isomers of C20-22 PUFA. the TRL-TAG sample was divided by the total number of moles of all fatty acids in the PHFO meal and in the TRLTAG sample respectively, and multiplied by 100 .

\section{Statistical analysis}

All statistical analysis was completed using Data Desk 4.1 (Data Description Inc., New York, NY, USA). Repeated-measures ANOVA, using meal as the independent variable, investigated changes in the postprandial variations of plasma TAG, TRLTAG, cholesterol, and NEFA concentrations, and for TRLTAG and NEFA, fatty acid composition. The postprandial data were expressed in summary form, i.e. area under the postprandial curve (AUC), incremental AUC, maximum postprandial concentration $\left(\mathrm{C}_{\max }\right)$ and time to maximal postprandial concentrations $\left(\mathrm{T}_{\max }\right)$ for each individual for each of the three meals. Time to minimal postprandial concentration $\left(\mathrm{C}_{\min }\right)$ was calculated for plasma NEFA concentrations. The AUC was calculated using the trapezium rule, as recommended by Matthews et al. (1990). Two-way ANOVA, using subject and meal as the independent variables, was used to investigate significant differences of these summary variables. Post hoc statistical analysis was completed using the least significant difference, which determines the criterion to identify a significant difference between group means (Snedecor \& Cochran, 1989). Pearson correlation coefficients were calculated for fasting concentrations of TAG, TRL-TAG, cholesterol and NEFA with the postprandial AUC and $C_{\max }$. The level of statistical significance was set at $\alpha=0.05$ and the $P$ values quoted are two-sided. TRLTAG and NEFA composition data were log-transformed to give data a normal Gaussian distribution.

\section{Results}

Baseline characteristics of the eight participants are shown in Table 3.

Postprandial plasma triacylglycerol, triacylglycerol-rich lipoprotein-triacylglycerol, cholesterol and non-esterified fatty acid response

All three test meals elicited significant postprandial responses in plasma total TAG, TRL-TAG, cholesterol and NEFA $(P<0 \cdot 05)$. Peak plasma TAG and TRL-TAG concentrations occurred $2 \mathrm{~h}$ after consumption of the test meals and returned to fasting 
Table 3. Age, body mass index, fasting total cholesterol, triacylglycerol, glucose and $\gamma$-glutamyl transferase (GT) of the study participants

\begin{tabular}{|c|c|c|c|c|c|c|}
\hline Participant & Age (years) & BMI $\left(\mathrm{kg} / \mathrm{m}^{2}\right)$ & Cholesterol (mmol/l) & Triacylglycerol (mmol/l) & Glucose $(\mathrm{mmol} / \mathrm{l})$ & $\gamma$-GT $(\mathrm{U} / \mathrm{l})$ \\
\hline 1 & 27 & $23 \cdot 25$ & $4 \cdot 86$ & 0.98 & 3.58 & $16 \cdot 0$ \\
\hline 2 & 21 & $25 \cdot 18$ & $4 \cdot 34$ & 0.67 & $5 \cdot 13$ & $11 \cdot 0$ \\
\hline 3 & 23 & 28.69 & $5 \cdot 27$ & 0.97 & $6 \cdot 06$ & $13 \cdot 0$ \\
\hline 4 & 30 & 22.46 & $4 \cdot 80$ & $1 \cdot 21$ & $5 \cdot 29$ & $6 \cdot 0$ \\
\hline 5 & 30 & $27 \cdot 33$ & $5 \cdot 07$ & 1.50 & $6 \cdot 34$ & $13 \cdot 0$ \\
\hline 6 & 27 & 27.90 & $4 \cdot 78$ & 2.07 & 4.40 & 23.5 \\
\hline 7 & 26 & $25 \cdot 60$ & $3 \cdot 74$ & $1 \cdot 30$ & $5 \cdot 14$ & $22 \cdot 0$ \\
\hline 8 & 25 & $25 \cdot 14$ & $5 \cdot 50$ & 1.99 & 4.50 & $25 \cdot 0$ \\
\hline Mean & $26 \cdot 1$ & $25 \cdot 7$ & $4 \cdot 8$ & $1 \cdot 33$ & $5 \cdot 1$ & 14.9 \\
\hline SD & $3 \cdot 1$ & $2 \cdot 2$ & 0.5 & 0.5 & 0.9 & $8 \cdot 1$ \\
\hline
\end{tabular}

concentrations by $8 \mathrm{~h}$ (Table 4, Fig. 1 and Fig. 2). There was a marked variability in the postprandial response between individuals for TAG, TRL-TAG, cholesterol $(P<0.001)$ and NEFA $(P<0 \cdot 001)$ and also a statistically significant postprandial time effect (TAG, TRL-TAG, NEFA, $P<0.0001$; cholesterol, $P=0.004)$. There was no difference in the postprandial plasma TAG, TRL-TAG, cholesterol or NEFA responses following the three test meals. As fasting plasma TAG concentrations were correlated with TAG-C ${ }_{\max }(r 0.77 ; P<0.0001)$ and TAGAUC $(r 0.87 ; P<0.0001)$, the incremental AUC was calculated. There was no difference in any of the summary variables (AUC, incremental AUC, $\mathrm{T}_{\max }, \mathrm{C}_{\max }$ ) between meals (Table 5). NEFA concentrations were depressed at $2 \mathrm{~h}$ following all three test meals (Table 4; Fig. 3).

\section{Triacylglycerol-rich lipoprotein-triacylglycerol fatty acid composition}

Partially hydrogenated fish oil test meal. The following fatty acids showed a marked elevation in TRL-TAG $4 \mathrm{~h}$ postprandially following ingestion of the PHFO test meal; $18: 0,16: 1$ trans, and $18: 1$ trans and returned to fasting levels $8 \mathrm{~h}$ postprandially. There was also a non-significant increase in $14: 0,16: 0,16: 1 \mathrm{cis}, 18: 1 \mathrm{cis}$, and $20: 1 \mathrm{cis}$ following the PHFO test meal. The fatty acid composition of the $4 \mathrm{~h}$ TRL-TAG samples, expressed as a percentage of total TRL-TAG fatty acids, is shown in Fig. 4. The following fatty acids were over-represented in the chylomicron fraction; $16: 0$, 16:1cis, 18:1cis and 18:2cis,cis, while 16:1trans, 18:1trans and $18: 2$ trans,trans were under-represented. Longer-chain fatty acids (C20-22) were either not present, or present in very small quantities, in the chylomicron fraction (TRL-TAG) despite their large contribution in the PHFO meal.

Lard test meal. A statistically significant meal $\times$ time interaction was demonstrated after the lard test meal was consumed, as $16: 0,18: 0$, and $18: 1$ cis increased $4 \mathrm{~h}$ postprandially. In addition 14:0 and 16:1cis showed a statistically non-significant increase.

Palm oil test meal. After the palm oil test meal was consumed, the increase in 10:0 and 16:0 was statistically

Table 4. Postprandial plasma triacylglycerol (TAG), TAG-rich lipoprotein-TAG (TRL-TAG), cholesterol and non-esterified fatty acid responses to the ingestion of a partially hydrogenated fish oil (PHFO), lard or palm oil test meal by healthy volunteers

(Mean values and standard deviations for eight participants)

Time after test meal (h)

\begin{tabular}{|c|c|c|c|c|c|c|c|c|c|c|c|c|c|}
\hline & \multicolumn{2}{|c|}{0} & \multicolumn{2}{|c|}{2} & \multicolumn{2}{|c|}{4} & \multicolumn{2}{|c|}{6} & \multicolumn{2}{|c|}{8} & \multicolumn{3}{|c|}{$\begin{array}{c}\text { Statistical analysis of effect } \\
(\text { ANOVA; } P \text { ) }\end{array}$} \\
\hline & Mean & SD & Mean & SD & Mean & SD & Mean & SD & Mean & SD & Meal & Time & Meal $\times$ time \\
\hline \multicolumn{14}{|c|}{ Plasma TAG (mmol/l) } \\
\hline PHFO & $1 \cdot 24$ & 0.34 & $1.60^{*}$ & 0.45 & $1.59^{\star}$ & 0.62 & $1 \cdot 26$ & 0.33 & $1 \cdot 02^{*}$ & 0.28 & \multirow[t]{3}{*}{ NS } & \multirow[t]{3}{*}{$<0.001$} & \multirow[t]{3}{*}{ NS } \\
\hline Lard & $1 \cdot 37$ & 0.31 & $1 \cdot 86^{*}$ & 0.45 & $1 \cdot 73^{*}$ & 0.60 & 1.43 & 0.48 & $1 \cdot 13^{*}$ & 0.37 & & & \\
\hline Palm oil & $1 \cdot 36$ & 0.43 & $1 \cdot 86^{*}$ & 0.62 & 1.54 & 0.70 & $1 \cdot 34$ & 0.37 & $1 \cdot 12^{*}$ & 0.30 & & & \\
\hline PHFO & 0.51 & 0.22 & $0.87^{\star}$ & 0.37 & 0.76 & 0.46 & 0.48 & 0.27 & 0.32 & 0.19 & \multirow[t]{3}{*}{ NS } & \multirow[t]{3}{*}{$<0.001$} & \multirow[t]{3}{*}{ NS } \\
\hline Lard & 0.57 & 0.24 & $1.05^{*}$ & 0.41 & $0.92^{*}$ & 0.57 & 0.63 & 0.42 & 0.44 & 0.29 & & & \\
\hline Palm oil & 0.50 & 0.30 & $0.98^{*}$ & 0.51 & 0.69 & 0.55 & 0.60 & 0.23 & 0.41 & 0.20 & & & \\
\hline \multicolumn{14}{|c|}{ Cholesterol (mmol/l) } \\
\hline PHFO & 4.87 & 0.59 & 4.93 & 0.61 & 4.94 & 0.59 & $4 \cdot 98^{*}$ & 0.60 & $5 \cdot 03^{\star}$ & 0.66 & \multirow[t]{3}{*}{ NS } & \multirow[t]{3}{*}{0.004} & \multirow[t]{3}{*}{ NS } \\
\hline Lard & $5 \cdot 11 \dagger$ & 0.69 & 5.03 & 0.67 & 5.04 & 0.66 & $5 \cdot 13 \dagger$ & 0.64 & $5 \cdot 10$ & 0.65 & & & \\
\hline Palm oil & $4.98 \ddagger$ & 0.66 & $5 \cdot 00$ & 0.68 & 4.95 & 0.68 & $5 \cdot 01 \ddagger$ & 0.53 & $5 \cdot 11^{\star}$ & 0.62 & & & \\
\hline \multicolumn{14}{|c|}{ NEFA (mmol/l) } \\
\hline PHFO & 0.27 & 0.19 & 0.19 & 0.11 & $0.37^{\star}$ & 0.13 & $0.55^{\star}$ & 0.25 & $0.63^{*}$ & 0.24 & \multirow[t]{2}{*}{ NS } & \multirow[t]{2}{*}{$<0.001$} & \multirow[t]{2}{*}{ NS } \\
\hline Palm oil & 0.35 & 0.21 & 0.29 & 0.21 & 0.49 & 0.29 & $0.54^{\star}$ & $0 \cdot 18$ & $0.57^{\star}$ & 0.23 & & & \\
\hline
\end{tabular}

* Mean value was significantly different from that at fasting (time 0$)(P<0.05)$.

$\dagger$ Mean value was significantly different from that of the PHFO meal at the same time point $(P<0.05)$

$\ddagger$ Mean value was significantly different from that of the lard meal at the same time point $(P<0.05)$. 


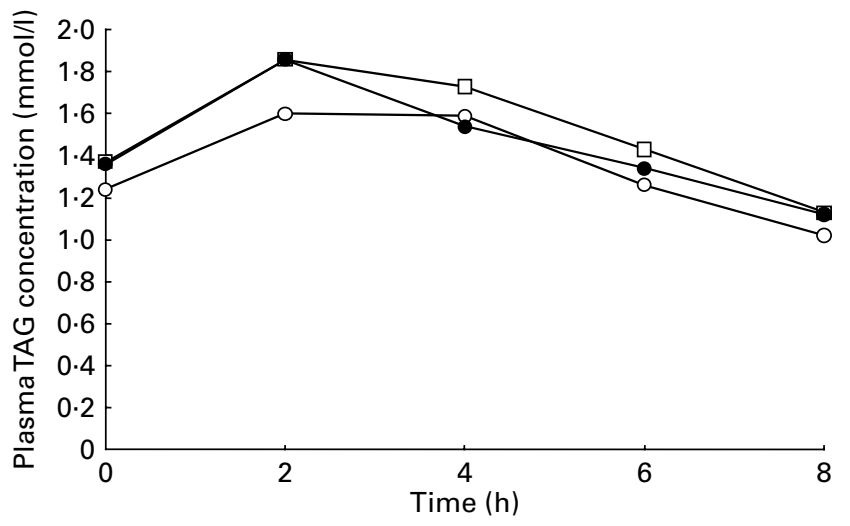

Fig. 1. Postprandial response of total plasma triacylglycerol (TAG) for each of the test meals: partially hydrogenated fish oil $\left(-O_{-}\right)$, lard $(-\square-)$ and palm oil (--).

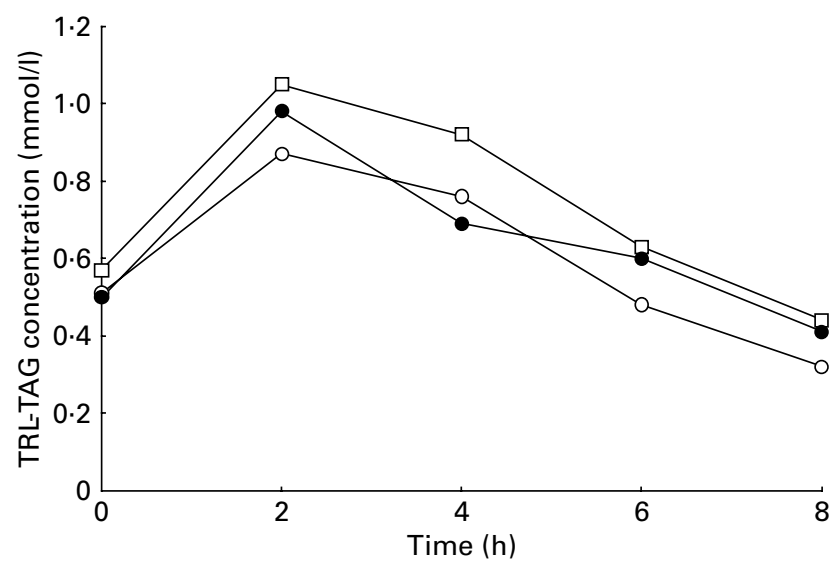

Fig. 2. Postprandial response of triacylglycerol-rich lipoprotein-triacylglycerol (TRL-TAG) for each of the test meals: partially hydrogenated fish oil (-O-),

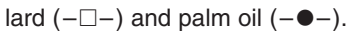

significant $4 \mathrm{~h}$ postprandially; $18: 1$ cis also increased, but this increase was not significant.

\section{Plasma non-esterified fatty acid composition}

The concentrations of individual fatty acids in the plasma NEFA pool at 0,4 and $8 \mathrm{~h}$ following ingestions of the PHFO, lard and palm oil test meals were derived from applying concentrations (\% w/w) of fatty acids to plasma NEFA concentrations $(\mathrm{mmol} / \mathrm{l})$. Significant meal $\times$ time interactions occurred after eating all three test meals.

Partially hydrogenated fish oil test meal. The following fatty acids were significantly increased in plasma NEFA, 4 and $8 \mathrm{~h}$ after the PHFO meal; $8: 0,10: 0,12: 0,14: 0$, $16: 0,18: 0,16: 1 \mathrm{cis}, 16: 1$ trans, $18: 2 \mathrm{cis}$, and $18: 1 \mathrm{cis}$ and $18: 1$ trans concentrations were statistically significantly increased at $8 \mathrm{~h}$.

Lard test meal. Concentrations of 8:0, and 18:0 were significantly increased 4 and $8 \mathrm{~h}$ postprandially, and $16: 0$, $16: 1 \mathrm{cis}, 18: 1 \mathrm{cis}$, and $18: 2 \mathrm{cis}$ were significantly increased at $8 \mathrm{~h}$.

Palm oil test meal. Concentrations of $16: 0$, and $18: 2 \mathrm{cis}$ were significantly increased 4 and $8 \mathrm{~h}$ postprandially and 18: 1 cis increased at $8 \mathrm{~h}$.

\section{Discussion}

Habitual fat intake and its effect on LDL, HDL and TAG concentrations have been studied extensively, including habitual TUFA intake. However, the acute postprandial effect of TUFA of marine origin on plasma lipids has not been widely investigated. In addition, since it has been well established that a prolonged and elevated acute postprandial response is associated with adverse metabolic events, we wanted to compare the acute postprandial lipaemic response to PHFO, which is high in TUFA, with lard and palm oil. These fats were chosen for the test meals because of their similar solidity and because they are all

Table 5. Summary variables for the postprandial response of plasma triacylglycerol (TAG), cholesterol and non-esterified fatty acids

(Mean values and standard deviations)

\begin{tabular}{|c|c|c|c|c|c|c|}
\hline & \multicolumn{2}{|c|}{ PHFO } & \multicolumn{2}{|c|}{ Lard } & \multicolumn{2}{|c|}{ Palm oil } \\
\hline & Mean & SD & Mean & SD & Mean & SD \\
\hline \multicolumn{7}{|l|}{ TAG } \\
\hline $\mathrm{AUC}(\mathrm{mmol} / \mathrm{l} \times 8 \mathrm{~h})$ & $11 \cdot 15$ & 2.98 & $12 \cdot 56$ & 3.36 & 11.96 & 3.37 \\
\hline IAUC $(\mathrm{mmol} / \mathrm{I} \times 8 \mathrm{~h})$ & $9 \cdot 91$ & $2 \cdot 71$ & $11 \cdot 18$ & 3.09 & $10 \cdot 60$ & 2.97 \\
\hline $\mathrm{TAG} \mathrm{T}_{\max }(\mathrm{h})$ & $3 \cdot 0$ & 2.39 & 2.25 & $1 \cdot 28$ & 2.75 & 1.49 \\
\hline TAG $\mathrm{C}_{\max }(\mathrm{mmol} / \mathrm{l})$ & 1.74 & 0.56 & 1.95 & 0.52 & 1.96 & 0.69 \\
\hline \multicolumn{7}{|l|}{ Cholesterol } \\
\hline $\mathrm{AUC}(\mathrm{mmol} / \mathrm{l} \times 8 \mathrm{~h})$ & 39.59 & $4 \cdot 81$ & $40 \cdot 61$ & $5 \cdot 24$ & $40 \cdot 00$ & $5 \cdot 00$ \\
\hline IAUC (mmol/I $\times 8 \mathrm{~h})$ & 34.72 & $4 \cdot 23$ & $35 \cdot 50$ & 4.57 & 35.03 & $4 \cdot 36$ \\
\hline Cholesterol $\mathrm{T}_{\max }(\mathrm{h})$ & $7 \cdot 25$ & 1.04 & $5 \cdot 50$ & $2 \cdot 33$ & $6 \cdot 00$ & $3 \cdot 21$ \\
\hline Cholesterol $\mathrm{C}_{\max }(\mathrm{mmol} / \mathrm{l})$ & $5 \cdot 08$ & 0.65 & $5 \cdot 19$ & 0.68 & $5 \cdot 16$ & 0.60 \\
\hline \multicolumn{7}{|l|}{ NEFA } \\
\hline $\mathrm{AUC}(\mathrm{mmol} / \mathrm{l} \times 8 \mathrm{~h})$ & $3 \cdot 12$ & $1 \cdot 12$ & 3.56 & 1.83 & 3.55 & 1.57 \\
\hline IAUC $(\mathrm{mmol} / \mathrm{I} \times 8 \mathrm{~h})$ & $2 \cdot 85$ & 1.03 & $3 \cdot 22$ & 1.72 & 3.20 & 1.47 \\
\hline$N E F A T_{\min }(h)$ & $1 \cdot 25$ & 1.04 & 1.75 & 1.98 & 1.50 & 0.93 \\
\hline NEFA $C_{\min }(\mathrm{mmol} / \mathrm{l})$ & 0.17 & 0.11 & 0.23 & 0.12 & 0.23 & 0.12 \\
\hline
\end{tabular}

PHFO, partially hydrogenated fish oil; AUC, area under the curve; IAUC, incremental area under the curve; $T_{\max }$, time to reach maximum concentration; $C_{\max }$, maximum concentration; $T_{\min }$, time to reach minimum concentration; $\mathrm{C}_{\mathrm{min}}$, minimum concentration. 


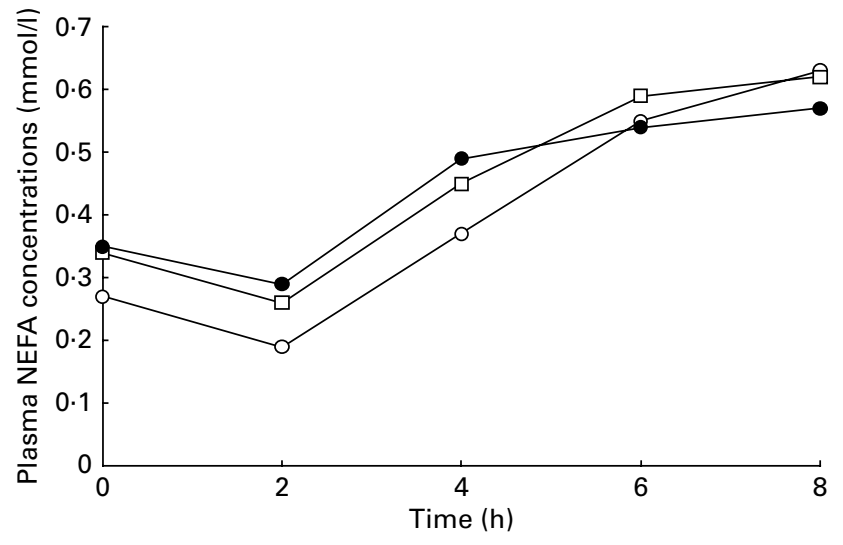

Fig. 3. Postprandial response of plasma NEFA for each of the test meals: partially hydrogenated fish oil $\left(-\mathrm{O}_{-}\right)$, lard $(-\square-)$ and palm oil (--)

used by the food industry. Consumption of all three high-fat test meals resulted, as expected, in pronounced postprandial lipaemia. There was, however, no significant difference in the postprandial response in plasma TAG, TRL-TAG, total cholesterol or plasma NEFA, measured as the AUC, between the three test meals. A previous study (Shishebor, 1997) also showed no difference in the postprandial lipaemic response to PHSO compared with native soyabean oil, in healthy participants. A lower incremental AUC of TRL-TAG was shown, however, following ingestion of the PHSO meal in that study and a statistically nonsignificant lower TRL-TAG incremental AUC was shown following the PHFO meal in the present study. This difference could be due to preferential oxidation of TUFA, and can be supported by studies which have shown lower human tissue levels of TUFA compared with dietary intake (London et al. 1991; Cantwell et al. 2005).

We were specifically interested in examining how fatty acids specific to each test meal increased in TRL-TAG during the $8 \mathrm{~h}$ following consumption of each meal. The concentration of $18: 0$ and $18: 1$ cis fatty acids showed marked elevations in TRL-TAG $4 \mathrm{~h}$ following ingestion of the lard meal, which mirrored the fatty acid composition of the meal, as $55 \%$ of the total fatty acids were from 18:0 and $18: 1 \mathrm{cis}$. Similarly, there was a significant increase in palmitic acid (16:0) in the TRL-TAG $4 \mathrm{~h}$ postprandially after the palm oil meal, as $42 \%$ of the total fatty acid composition was contributed by $16: 0$.

In contrast, 18:0, 16:1trans and 18:1trans fatty acids showed marked elevations in TRL-TAG $4 \mathrm{~h}$ after the PHFO meal even though these fatty acids provided only $21 \%$ of the total fatty acids. In addition, there was no marked elevation of the longer-chain fatty acids (C20-22, cis or trans isomers) even though they provided $40 \%$ of the total fatty acids in the PHFO meal. Long-chain fatty acids ( $>20$ carbons) were clearly not incorporated into TRL-TAG to the same extent as fatty acids with carbon chain lengths between 16 and 18 due to decreased absorption. Clearly there was a decreased absorption of fatty acids with increasing chain length, a finding that is consistent with previous studies (Filer et al. 1969; Peters et al. 1991).

Studies in rats have indicated that the absorption of the long-chain SFA behenic acid $(22: 0)$ is highly dependent on the TAG source. The amount of $22: 0$ absorbed from groundnut oil $(55 \%)$ was significantly greater than that absorbed from caprenin $(11 \%)$; also there was reduced absorption with increasing $22: 0$ concentrations $(3.6 \%$ fatty acids in groundnut oil and $46.6 \%$ of the fatty acids in caprenin). However, Webb \& Sanders (1991) have shown that low-melting fatty acids co-ingested with 22:0 act as solvents, thereby increasing uptake of 22:0 into the mixed micellar phase. The PHFO test meal in the present study had a low concentration of $22: 0$ (3.6\% of total fatty acids) similar to groundnut oil, but in addition had almost no low-melting fatty acids $(0.1 \% ; 12: 0)$ compared with groundnut oil $(46 \% ; 12: 0)$. Therefore, a low absorption of $22: 0$ in PHFO, similar to the absorption of behenic acid in caprenin (11\%), would be expected. Whether this explanation can be extended to other

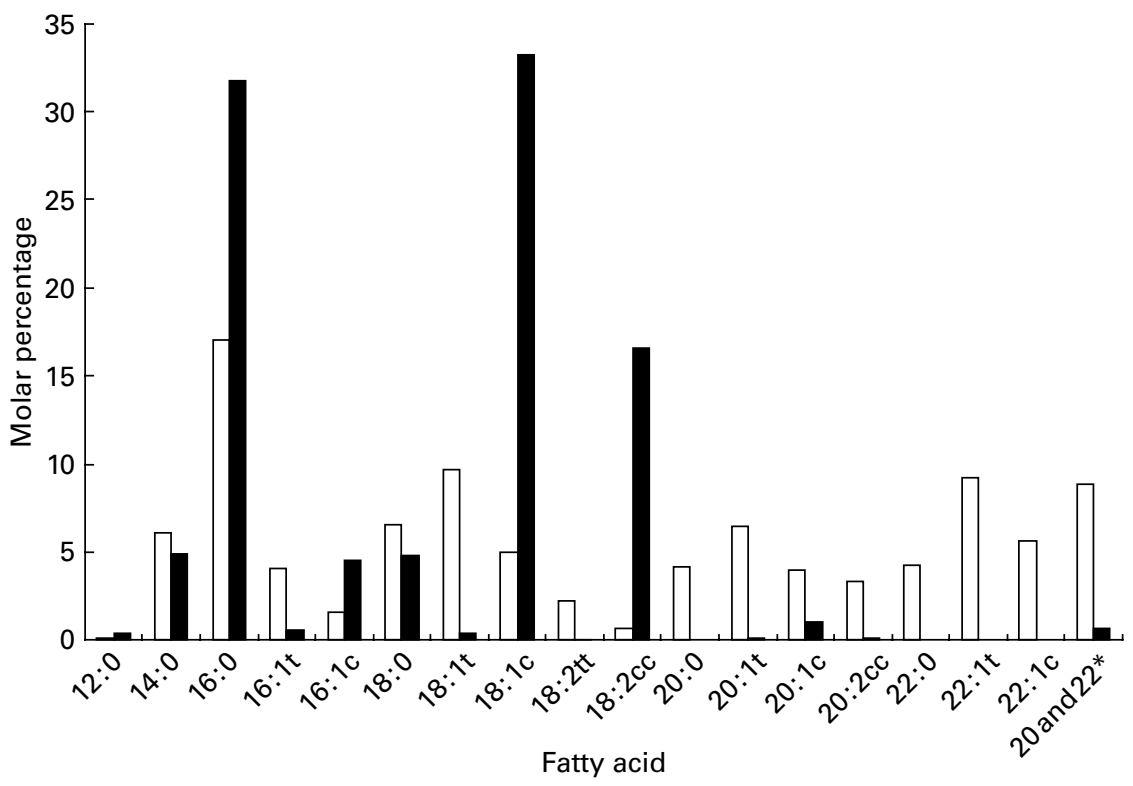

Fig. 4. Mean molar proportions of different fatty acids in chylomicron triacylglycerol $(n 8$; $\square$ ) and the partially hydrogenated fish oil meal ( $\square$ ). $t$, Trans; c, cis. * Trans fatty acid isomers of C20-22 PUFA. 
long-chain fatty acids (both cis and trans unsaturated geometric isomers) is questionable, although this mechanism may also explain the decreased recovery of other long-chain fatty acids in TRL-TAG following ingestion of the PHFO meal. In total long-chain fatty acids constituted only $3 \%$ of total fatty acids in the TRL-TAG $4 \mathrm{~h}$ postprandially, compared with $40 \%$ of total fatty acids in the PHFO test meal. The decreased absorption of long-chain fatty acids may explain why there was no difference in the postprandial TRL-TAG response shown following ingestion of a test meal which has a very high TUFA content, a similar SFA content and a lower PUFA content compared with the palm oil and lard test meals.

In general, plasma NEFA concentrations reflected the major fatty acid constituents of the test meals, a finding that is consistent with previous studies (Frayn et al. 1996). However, the increase in long-chain fatty acids (18-22cis and trans) following consumption of the PHFO test meal was not statistically significant. It has been estimated that almost $90 \%$ of the fatty acids found in NEFA in the late postprandial period are as a result of 'spillover' from lipoprotein lipase-derived fatty acids into the plasma (Frayn et al. 1997). It has also been shown that SFA and trans fatty acid isomers are preferentially incorporated into positions 1 and 3 of the TAG and PUFA at the sn- 2 position (Hølmer, 1998). Since lipoprotein lipase preferentially hydrolyses fatty acids at position 1 and 3 (Deckelbaum et al. 1990), it seems possible that trans fatty acids from TRL-TAG could be more rapidly hydrolysed than their cis isomers. However, in a study by Summers et al. (1999), subjects who were fed TAG with specific fatty acids enriched at positions 1 and 3 showed no specificity of lipoprotein lipase on palmitic, stearic or oleic acids. In addition, Summers et al. (2000) found no difference in adipose tissue extraction (lipoprotein lipase-mediated hydrolysis) of specific fatty acids. However, they did note that EPA $(20: 5 n$-3), but not DHA (22:6n$3)$, was under-represented in chylomicrons compared with the composition of a test meal.

In summary, there was no significant difference in the postprandial response in plasma TAG, TRL-TAG, total cholesterol or plasma NEFA, measured as the AUC, between the PHFO, lard or palm oil test meals. The postprandial TRL-TAG response to PHFO was expected to be higher than the response following lard and palm oil, as the fatty acid composition of PHFO was significantly higher in TUFA, lower in MUFA, slightly lower in PUFA and similar in SFA content compared with lard and palm oil test meals. The absence of a higher postprandial response following ingestion of PHFO compared with lard and palm oil could be as a result of reduced absorption and increased oxidation of long-chain fatty acids (both cis and trans isomers). Although the acute postprandial effect of PHFO was no worse than the response to lard and palm oil in this group of healthy males, further studies should be carried out in other groups who could respond differently; for example, those with diabetes or heart disease.

\section{Acknowledgements}

Support from the Strategic Research and Development Fund, Dublin Institute of Technology, Kevin Street, Dublin 8, the Non-Commissioned Food Research Programme administered by the Department of Agriculture, Food and Rural Development and the National Dairy Council, Ireland, is gratefully acknowledged. We would like to thank Dr Anne-Marie Tully and Dr Enda Noone for their advice with laboratory analysis. We are grateful for the editorial assistance of the NCI CCR Fellows' Editorial Board.

\section{References}

Almendingen K, Jordal O, Kierulf P, Sandstad B \& Pedersen JI (1995) Effects of partially hydrogenated fish oil, partially hydrogenated soybean oil, and butter on serum lipoproteins and Lp(a) in men. $J$ Lipid Res 36, 1370-1384.

Ascherio A, Hennekens CH, Buring JE, Master C, Stampfer MJ \& Willett WC (1994) Trans fatty acid intake and risk of myocardial infarction. Circulation 89, 94-101.

Cantwell MM, Gibney MJ, Cronin D, Younger KM, O'Neill JP, Hogan L \& Flynn MAT (2005) Development and validation of a food frequency questionnaire for the determination of detailed fatty acid intakes. Public Health Nutr 8, 97-107.

Deckelbaum RJ, Hamilton JA \& Moser A (1990) Medium-chain versus long-chain triacylglycerol emulsion hydrolysis by lipoprotein lipase and hepatic lipase: implications for the mechanisms of lipoprotein lipase. Biochemistry 29, 1136-1142.

Department of Health (1991) Dietary Reference Values for Food Energy and Nutrients for the United Kingdom. Report on Health and Social Subjects, no. 41. London: HM Stationery Office.

Dole VP (1956) A relation between non-esterified fatty acids in plasma and the metabolism of glucose. J Clin Invest 38, 150-154.

Expert Panel on Detection, Evaluation and Treatment of High Blood Cholesterol in Adults (2001) Executive summary of the report of the National Cholesterol Education Program (NCEP). Expert Panel on Detection, Evaluation and Treatment of High Blood Cholesterol in Adults (Adult treatment Panel III). JAMA 285, 2486-2497.

Filer LJ, Mattson FH \& Fomon SJ (1969) Triglyceride configuration and fat absorption by the human infant. J Nutr 99, 293-298.

Folch L, Lees M \& Sloane-Stanley GHS (1957) A simple method for the isolation and purification of total lipides from animal tissues. J Biol Chem 226, 497-509.

Frayn KN, Summers LKM \& Fielding BA (1997) Regulation of the plasma non-esterified fatty acid concentration in the postprandial state. Proc Nutr Soc 56, 713-721.

Frayn KN, Williams CM \& Arner P (1996) Are increased plasma non-esterified fatty acid concentrations a risk marker for coronary heart disease and other chronic diseases? Clin Sci 90, 243-253.

Gibney MJ \& Bolton-Smith C (1988) The effect of a dietary supplement of $n-3$ polyunsaturated fat on platelet lipid composition, platelet function and platelet plasma membrane fluidity in healthy volunteers. Br J Nutr 60, 5-12.

Grundy SM \& Mok HYI (1976) Chylomicron clearance in normal and hyperlipidemic man. Metabolism 25, 1225-1239.

Hodgson JM, Wahlqvist ML, Boxall JA \& Balazs ND (1996) Platelet trans fatty acids in relation to angiographically assessed coronary artery disease. Atherosclerosis 120, 147-154.

Hølmer G (1998) Biochemistry of trans monoenoic fatty acids. In Trans Fatty Acids in Human Nutrition, pp. 163-189 [JL Sebedio and WW Christie, editors]. Dundee: The Oily Press Ltd.

Judd JT, Clevidence BA, Muesing RA, Wittes J, Sunkin ME \& Podczasy JJ (1994) Dietary trans fatty acids: effects on plasma lipids and lipoproteins of healthy men and women. Am J Clin Nutr 59, 861-868.

Karpe F, Bard JM, Steiner G, Carlson LA, Fruchart JC \& Hamsten A (1993) HDLs and alimentary lipaemia. Studies in men with previous myocardial infarction at a young age. Arterioscler Thromb 13, $11-22$. 
Lichtenstein AH, Ausman LM, Carrasco W, Jenner JL, Ordovas JM \& Schaefer EJ (1993) Hydrogenation impairs the hypolipidaemic effect of corn oil in humans. Hydrogenation, trans fatty acids, and plasma lipids. Arterioscler Thromb 13, 154-161.

London SJ, Sacks FM, Caesar J, Stampfer MJ, Siguel E \& Willett WC (1991) Fatty acid composition of subcutaneous adipose tissue and diet in postmenopausal women. Am J Clin Nutr 54, 340-345.

Matthews JNS, Altman DG, Campbell \& Royston P (1990) Analysis of serial measurements in medical research. BMJ 300, 230-235.

Mensink RP \& Katan MB (1990) Effect of dietary trans fatty acids on high-density and low-density lipoprotein cholesterol levels in healthy subjects. New Engl J Med 323, 439-445.

Mensink RP, Zock PL, Katan MB \& Hornstra G (1992) Effect of dietary cis and trans fatty acids on serum lipoprotein (a) levels in humans. J Lipid Res 33, 1493-1501.

Muller H, Jordal O, Seljeflot I, Kierulf P, Kirkhus B, Ledsaak O \& Pedersen JI (1998) Effect on plasma lipids and lipoproteins of replacing partially hydrogenated fish oil with vegetable fat in margarine. Br J Nutr 80, 243-251.

National Academy of Sciences (2002) Dietary Reference Intakes for Energy, Carbohydrate, Fiber, Fat, Fatty Acids, Cholesterol, Protein, and Amino Acids. Washington, DC: National Academies Press.

Nestel PM, Noakes M, Belling B, Mc Arthur R, Clifton P, Janus E \& Abbey M (1992) Plasma lipoprotein and lipid Lp(a) changes with substitution of elaidic acid for oleic acid in the diet. J Lipid Res $\mathbf{3 3}$, 1029- 1036.

Patsch JR, Miesenbock K, Hopferwieser T, Muhlberger V, Knapp E, Dunn JK, Gotto AM \& Patsch W (1992) Relation of triglyceride metabolism and coronary artery disease. Studies in the postprandial state. Arterioscler Thromb 12, 1336-1345.
Peters JC, Holcombe BN, Hiller LK \& Webb DR (1991) Caprenin 3: absorption and caloric value in adult humans. J Am College Toxicol 10, $357-367$.

Shimizu S, Tani Y, Yamada H, Tabata M \& Murachi T (1980) Enzymatic determination of serum-free fatty acids: A colorimetric method. Anal Biochem 107, 193-198.

Shishebor F (1997) Nutritional factors affecting postprandial lipaemia. PhD Thesis, University of Dublin, Trinity College.

Snedecor GW \& Cochran WG (1989) Analysis of variance. In Statistical Methods, 8th ed. pp. 217-246. New York: Wiley.

Summers LKM, Barnes SC, Fielding BA, Beysen C, Ilic V, Humphreys SM \& Frayn KM (2000) Uptake of individual fatty acids into adipose tissue in relation to their presence in the diet. Am J Clin Nutr 71, 1470-1477.

Summers LKM, Fielding BA, Herd SL, Ilic V, Clark ML, Quinlan PT \& Frayn KN (1999) Use of structured triaclyglycerols containing predominantly stearic and oleic acids to probe early events in metabolic processing of fat. J Lipid Res 40, $1890-1893$.

Webb DR \& Sanders RA (1991) Caprenin 1. Digestion, absorption, and rearrangement in thoracic duct-cannulated rats. J Am College Toxicol 10, 325-340.

Willett WC, Stampfer MJ, Manson JE, Colditz GA, Speizer FE, Rosner BA \& Hennekens CH (1993) Intake of trans fatty acids and risk of coronary heart disease among women. Lancet 341, $581-585$.

Zilversmit DB (1979) Atherosclerosis: a postprandial phenomenon. Circulation 60, 473-485.

Zock PL \& Katan MB (1992) Hydrogenation alternatives, effects of trans fatty acids and stearic acid versus linoleic acid on serum lipids and lipoproteins in humans. J Lipid Res 33, 399-410. 